\title{
Some benefits of improving urban air quality from the perspective of Ho Chi Minh City people
}

\author{
Nguyen Tan Danh ${ }^{1 *}$, Le Minh Quang ${ }^{2}$ \\ ${ }^{1}$ IT Faculty, FPT University, Ho Chi Minh City, 700000, Vietnam. \\ ${ }^{2}$ Language Faculty, Ho Chi Minh City Open University, Ho Chi Minh City, Vietnam, 700000, \\ Vietnam
}

\begin{abstract}
In addition to the hot weather with an extremely high UV index, the air quality in some big cities of Vietnam also alarming. Air pollution will have a large impact on urban development and, above all, people's health. The results of air pollution monitoring over the past time in Ho Chi Minh City in some locations show that dust pollution and fine dust concentration (PM2.5) in the air of the Department of Natural Resources and Environment of Ho Chi Minh City are still high and at an alarming level. This is a problem of Ho Chi Minh City, Vietnam, and a matter of concern in other countries, especially Asian countries. A few years ago, this issue was mentioned, but now it still causes frustration. The article discusses the factors that affect the air quality, and for that reason the people of the city in particular and this study must take this issue seriously and need to have effective measures.
\end{abstract}

\section{Introduction}

Air pollution is an environmental issue of primary concern in cities around the world. According to the World Health Organization database for the year 2018, more than $80 \%$ of urban residents live in an atmosphere that does not meet the WHO's recommended standards [1].

Compared to other cities in Vietnam, the problem of air pollution, especially dust pollution in Ho Chi Minh city is considered to be more serious. Sources of pollution in this city include emissions from vehicles, construction activities, civil activities, industrial production activities, etc. About $70 \%$ of the smoke and dust causing in this big city is due to traffic activities. The health impact of air pollution on the people here is considered serious [2].

In recent years, Ho Chi Minh city has made efforts to implement air pollution mitigation measures such as piloting environment-friendly buses, planting 1 million trees by 2020, and installing additional air monitoring stations [3]. However, air pollution is still a big concern to urban residents, requiring more effective solutions to reduce air pollution [1].

\footnotetext{
* Corresponding author: doraemonof2050@gmail.com
} 


\section{Method}

This article presents the results of a survey of 50 households in Ho Chi Minh city on the measures to reduce air pollution that people want to prioritize implementation [4]. The collected information about people's wishes will be useful for the process of formulating policies to improve air quality to serve people's wishes.

On the basis of reviewing international experiences, the research has designed, made a list of solution options, and conducted a survey of Ho Chi Minh city residents on the solutions to reduce the import and export volume they want to favor implementation. Interviewees were asked to choose three priority solutions for implementation in the list of air pollution mitigation solutions [5].

An empirical choices approach is applied to estimate the economic benefits of air quality improvements for the population. Respondents make selection decisions in a hypothetical market designed to collect information about the possible benefits from improved air quality [6]. The level that people choose is a measure that reflects the economic benefits they perceive in terms of the improvement in air quality. Each resident surveyed was asked to answer 4 questions showing 4 different options. The options presented represent varying degrees of improvement in health risk reduction and greenery acreage.

\section{Results and disucssion}

\subsection{Select solutions to reduce air pollution of city residents}

The results of selecting solutions that people in this city want to prioritize are presented in Table 1. In the list of 4 solutions given, the group of two solutions that people want to prioritize (with the highest rate of choice) are: (1) Increase green tree planting activities and (2) Converting to using fuel with less air pollution.

Table 1. Percentage of priority solutions to improve air quality

\begin{tabular}{|c|l|c|}
\hline No & \multicolumn{1}{|c|}{ Solutions } & Ratio \\
\hline 1 & Increase green tree planting activities & $62 \%$ \\
\hline 2 & Converting to using fuel with less air pollution & $45 \%$ \\
\hline 3 & Public transport system development & $37 \%$ \\
\hline 4 & Apply strict emissions standards to vehicles & $29 \%$ \\
\hline
\end{tabular}

It can be seen that the most favored solutions by the city residents are also consistent with international experiences in the implementation and benefits of urban import and export reduction solutions.

With the solution of increasing greenery activities, urban green spaces, such as parks, rooftop gardens, roadside greenery systems and tree walls provide a wide range of ecosystem services to cities are paid attention in many places [4]. Many major cities around the world are making efforts to increase their green spaces. Recent studies show that green spaces can protect city dwellers from air pollution by removing/reducing certain pollutants that negatively affect health. Pollutants that can be significantly reduced in locations near green spaces include: PM10, PM2.5, NOx and O3. 
With the option of converting to using less polluting fuels, switching to low-carbon fuels and electric vehicles is also a popular choice in dealing with air pollution. The transition to electric vehicles could have great potential to reduce emissions that cause air pollution (i.e., $\mathrm{CO}, \mathrm{NOx}, \mathrm{VOC}, \mathrm{SO} 2)$. Other studies show that switching to electric vehicles can reduce $\mathrm{PM} 2.5$ and $\mathrm{O} 3$ emissions.

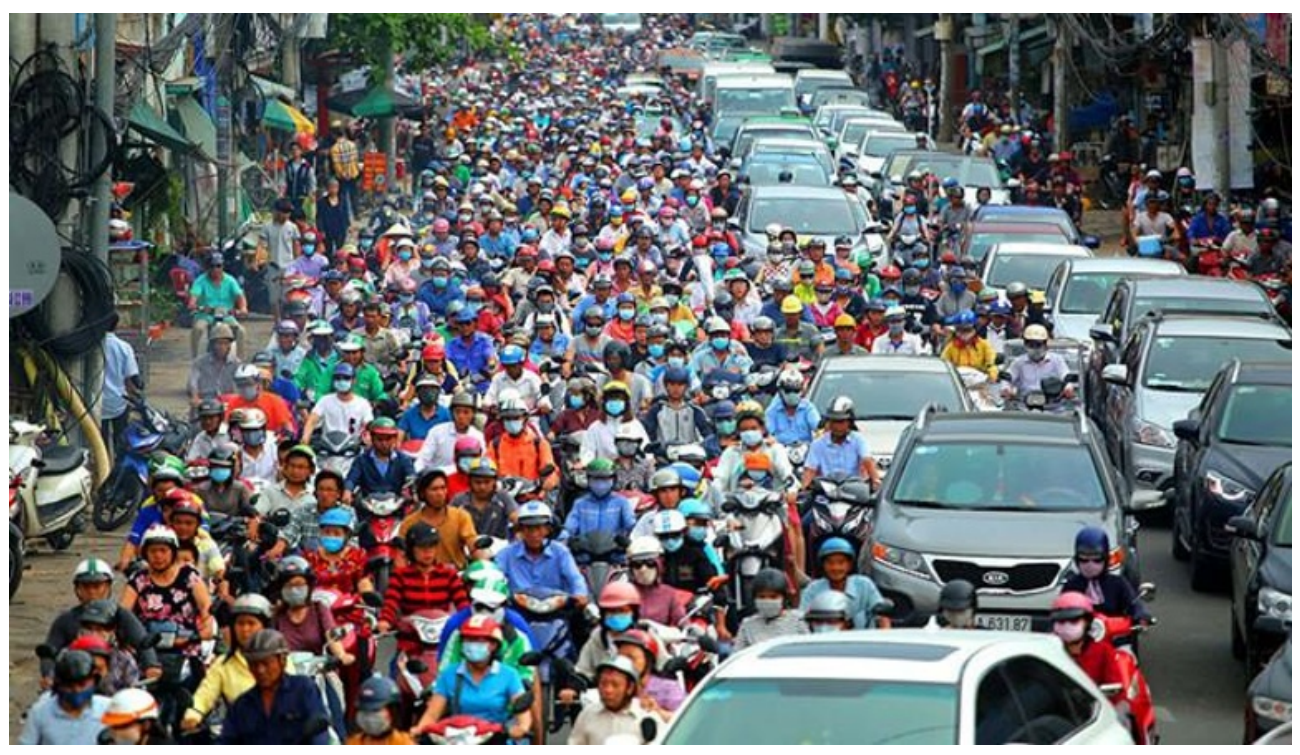

Fig. 1. Motorbike-a popular means of transport in Ho Chi Minh city

The public transport system allows the transportation of many people daily, is an environmentally friendly transport option. Among public transport forms, the BRT bus system has been increasingly deployed across some countries from America, Southeast Asia, and Europe. Studies show that BRT can reduce CO, NOx, PM2.5, and PM10 emissions. Increasing service frequency can also have a positive impact on reducing $\mathrm{CO} 2, \mathrm{NOx}$ emissions. However, it should be noted that if there is no change in urban transport regulations (e.g., restriction on private transport), public transport may not improve air quality [7].

\subsection{Some recommendations}

Obviously, air pollution at an alarming rate has been and is a common situation of many countries, especially Asian countries. A series of unsettled socio-economic problems have arisen such as a high air pollution level; that is, this once threatened many activities around the world.

Huge losses caused by air pollution have made us take into consideration are worth pondering [8]. The current environmental pollution situation, especially air pollution, is a real challenge for specialized agencies in enhancing accountability and implementing solutions to respond, not stop at declaration activities. Simple transmission, should avoid generic and cheering slogans [5]. First of all, this study needs to assess the impact on the environment and people's health caused by air pollution, then, what this study has to do is to guide citizens about health protection for the whole community. 


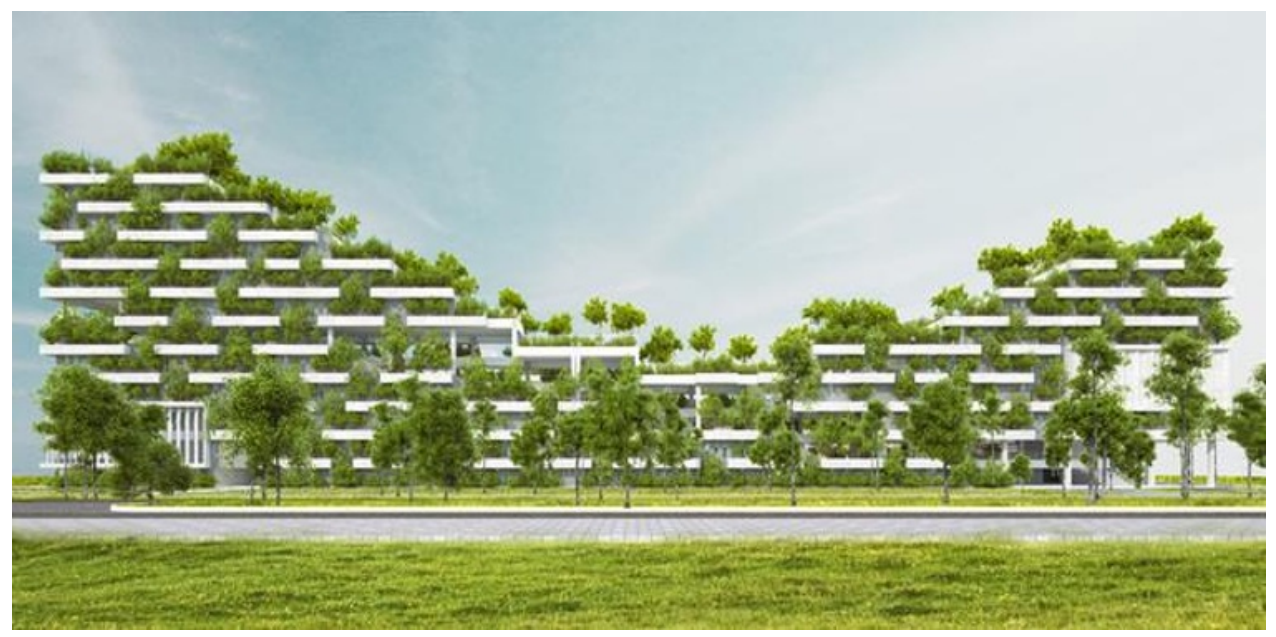

Fig. 2. Great architecture of FPT University

Then, to ensure ecological balance, maintain sustainable development, and protect quality of life, this study needs to identify planting trees as an important, necessary and urgent job, associated with the development process.not just for today, but for generations to come. Through tree planting activities to raise awareness about nature conservation and environmental protection for local people. In the face of increasingly severe climate change, erratic weather, planting trees is the natural, simple, cheapest way to cope and anyone can do it. This is a very practical activity to respond to actions to protect the environment and respond to climate change [7].

We should also use reusable bags to protect the environment. Although very convenient, plastic bags are not biodegradable, they can last in the environment for hundreds of years. Everyone needs to get used to reducing use - reusing - using recycled products [3] Therefore, this study can reduce our consumption, use recycled products instead of throwing them away.

\section{Conclusion}

This study reflects the economic benefits people perceive for the improvement of Ho Chi Minh city's air quality. The paper expresses people's interests in increasing green spaces and reducing air pollution-related deaths. Reducing the loss caused by air pollution will require the regulator's efforts and the efforts of prevention and self-protection of each individual, each household. The economic benefits estimated in this study reflect the benefits that people perceive about public solutions implemented by the regulators, but do not include the benefits associated with individual solutions people apply to protect themselves and their family from the risk of air pollution. The results of this Thisistudy's resultsor designing and evaluating the effectiveness of regulatory agencies' policies in protecting the air environment.

\section{Acknowledgements}

The author (Nguyen Tan Danh) would like to show thanks to FPT University where he is working. The co-author (Le Minh Quang) also likes to show thanks to Ho Chi Minh city Open Univeristy where he is taking an English course, for financial support.

\section{References}


1. Hao, J., \& Wang, L., Improving urban air quality in China: Beijing case study., J. Air Waste Manage. Assoc., 55 9, 1298-1305 (2005)

2. Pham, T. G., Perception of urban residential community in Ho Chi Minh City about the health risks caused by inundation., Science and Technology Development Journal. 17 98110 (2014)

3. Hoi, H. T., Impacts of Urbanization on the Environment of Ho Chi Minh City., In IOP Conference Series: Earth and Environmental Science, IOP Publishing, 505 1, 012035 (2020)

4. Cifuentes, L. A., Krupnick, A. J., O'Ryan, R., \& Toman, M. A., Urban air quality and human health in Latin America and the Caribbean., Inter American Development Bank (2005)

5. Danh, N. T., \& Hoi, H. T,. Effects of plastic waste to sea environment in Vietnam., In IOP Conference Series: Earth and Environmental Science, IOP Publishing, 351 1, 012023. (2019)

6. Leung, D. Y., Tsui, J. K., Chen, F., Yip, W. K., Vrijmoed, L. L., \& Liu, C. H., Effects of urban vegetation on urban air quality., Landscape Research, 36 2, 173-188 (2011).

7. Gulia, S., Nagendra, S. S., Khare, M., \& Khanna, I., Urban air quality management-A review., Atmos. Pollut. Res., 6 2, 286-304 (2015)

8. Dal Maso, M., Gao, J., Järvinen, A., Li, H., Luo, D., Janka, K., \& Rönkkö, T., Improving urban air quality measurements by a diffusion charger based electrical particle sensors-A field study in Beijing, China., Aerosol Air Qual. Res., 16 12, 3001-3011 (2016)

9. Nemet, G. F., Holloway, T., \& Meier, P., Implications of incorporating air-quality cobenefits into climate change policymaking., Environ. Res. Lett., 5 1, 014007 (2010) 